\title{
A Novel 3-Phenylethynyl-2-yl-oxy Quinoxaline Core Skeleton and Pharmacophore Model as a Hypoxia-inducible Factor Inhibitor
}

\author{
Young-Dae Gong* and Nam Sook Kang ${ }^{\dagger, *}$ \\ Innovative Drug Library Research Center, Department of Chemistry, Dongguk University-Seoul, Seoul 100-715, Korea \\ ${ }^{*}$ E-mail: ydgong@dongguk.edu \\ ${ }^{\dagger}$ Drug Discovery Platform Technology Team, Korea Research Institute of Chemical Technology, P.O. Box 107, \\ Singseongno, Yuseong-gu, Daejeon 305-600, Korea. "E-mail: nskang@krict.re.kr \\ Received July 22, 2010, Accepted September 13, 2010
}

Key Words: 3-Phenylethynyl-2-yl-oxy quinoxaline, Hypoxia-inducible factor (HIF), Drug-like core skeleton, Pharmacophore

The hypoxia-inducible factor (HIF) is a transcription factor induced by hypoxia that is degraded by ubiquitin-dependent proteasomes in normoxic conditions. HIF- $1 \alpha$ regulates the transcription of many genes involved in key aspects of cancer biology, including various immortalizations, maintenance of stem cell pools, cellular dedifferentiation, genetic instability, vascularization, metabolic reprogramming, autocrine growth factor signaling, invasion/metastasis, and treatment failure. ${ }^{1}$ As hypoxic tumor cells are resistant to conventional chemotherapy and radio-therapy, their presence exacerbates patient prognosis. $^{2-4}$

The importance of HIF-1 $\alpha$ in the mediation of normal and pathological processes has motivated considerable efforts to identify HIF-1 $\alpha$ inhibitors. Although a wealth of inhibitory compounds is available, synthesizing HIF- $1 \alpha$ inhibitors with a novel small-molecule core skeleton fitting individual HIF-1 $\alpha$ has proven to be a challenge. Many reports have described the development of anticancer agents targeting HIF-1 $\alpha$, but only a few anticancer agents, incorporating heterocyclic rings and several aromatic core skeletons, have been identified as inhibitors of HIF- $1 \alpha{ }^{5-6}$ We therefore attempted to develop novel and simple, drug-like, heterocyclic derivatives as inhibitors of HIF-1 $\alpha{ }^{7}$ By using the bioisostere concept based on benzene ring-fused, bicyclic HIF-1 $\alpha$ inhibitors, we designed scaffolds that combine the pyridine moiety found in the 3-phenylethynyl-2-yl-oxy quinoxaline ring system. ${ }^{8}$

Herein, we report initial evidence showing that compounds with a 3-phenylethynyl-2-yl-oxy quinoxaline core skeleton are selective HIF-1 $\alpha$ inhibitors, and therefore have potential to be anticancer agents. The aim of this study was to investigate the biochemical properties of HIF- $1 \alpha$ and identify new core skeleton inhibitors of HIF-1 $\alpha$. To identify such small-molecule inhibitors of HIF-1 $\alpha$, we screened 163 substituted quinoxaline derivatives using the HRE/SW480 stable cell line containing HRE-luc[pHTS-9XHRE-Luc]. Once HIF-1 $\alpha$ was induced, the hypoxia response element (HRE) promoter was activated by binding with HIF-1 $\alpha$, which in turn activated the reporter gene, luciferase. Therefore, the compounds can be tested for whether HIF- $1 \alpha$ activation is inhibited using this system. The 163 screened quinoxaline compounds represent 4,000 structurally diverse and druggable derivatives. ${ }^{9-11}$
The efficacy of the 163 compounds in inhibiting Hif-RGA cell proliferation was screened at a compound concentration of $5 \mu \mathrm{M}$ and the compounds that reproducibly inhibited growth by over $80 \%$ were selected. In the first round of screening, 18 compounds reproducibly exhibited an $\mathrm{IC}_{50}$ value below $2.5 \mu \mathrm{M}$. We found structural similarity for the 3-position of the substituted phenylethynyl group and the 2-position of yl-oxy group on the quinoxaline as hit compounds of HIF- $1 \alpha$ cell activities. Among them, the 2 hit compounds selected for further screening had the following structures: 6-amino-3-substituted phenylethynyl-2-yl-oxy quinoxaline (Figure 1, compound 3892) and 5-methoxy-3-phenylethynyl-2-yl-oxy quinoxaline (Figure 1, compound 3909). Preliminary structure-activity relationship studies of the 18 hit compounds indicated that the 3-phenylethynyl-2-yl-oxy quinoxaline moiety is critical to their HIF-1 $\alpha$ inhibitory activities, as shown in Figure 1.

As shown Figure 1, compounds 3819, 3892, 3909, and 3913 which have hydrophilic functional group at 5- or 6- position of benzene ring, were showed higher activities compared to proton or chloride or fluoride substituent at the same position. To clearly investigate the structure-activity relationship studies of the 18 compounds of the 3-phenylethynyl-2-yl-oxy quinoxaline hit compounds, we selected 5 known compounds $(\mathrm{R} 1 \sim \mathrm{R} 5)$ from the Prous site (http://prous.integrity.com) $)^{8,12-15}$ as HIF-1 $\alpha$ inhibitors and used them in the training set, as shown in Figure 2. After the 3D structures of these compounds were generated using CONCORD, ${ }^{16}$ they were minimized using GasteigerHuckel charges and conjugated gradient methods. The common pharmacophores were generated using the HipHop algorithm. ${ }^{17}$ Predefined pharmacophore features were used to automatically create the pharmacophore hypothesis model. The list of features of the minimum and maximum values was as follows: H-bond acceptor (Hba) 0 and 5, H-bond donor (Hbd) 0 and 5, Hydrophobic (Hy) 0 and 5. The compounds in the training set showed fit values ranging from 2.9 to 4.0 . We have previously reported this model. ${ }^{18}$

The pharmacophore mapping for reference compound R1 having fit value of 4.0 is shown in Figure 3. The green and cyan spheres represent the hydrogen-bond acceptor site and the hydrophobic sites, respectively. All compounds in the training set had a fit value of 2.9 or more. We focused on calculating the 


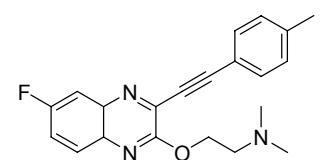

(a) 3761

$\left(2.5 \mu \mathrm{M}=84.87 \% ; \mathrm{IC}_{50} \mathrm{SD}=0.51 \mu \mathrm{M}\right)$

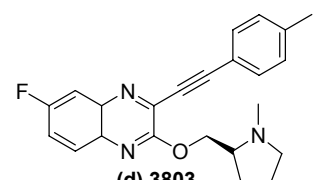

(d) 3803

$\left(2.5 \mu \mathrm{M}=87.03 \% ; \mathrm{IC}_{50} \mathrm{SD}=0.75 \mu \mathrm{M}\right)$

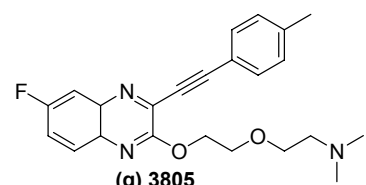

(g) 3805

$\left(2.5 \mu \mathrm{M}=97.94 \% ; \mathrm{IC}_{50} \mathrm{SD}=0.32 \mu \mathrm{M}\right)$

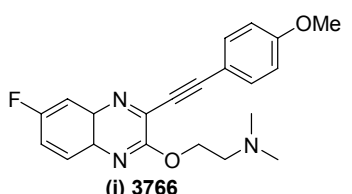

$\left(2.5 \mu \mathrm{M}=81.55 \% ; \mathrm{IC}_{50} \mathrm{SD}=0.90 \mu \mathrm{M}\right)$

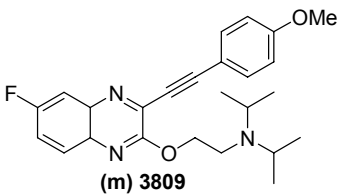

$\left(2.5 \mu \mathrm{M}=80.84 \% ; \mathrm{IC}_{50} \mathrm{SD}=2.09 \mu \mathrm{M}\right)$

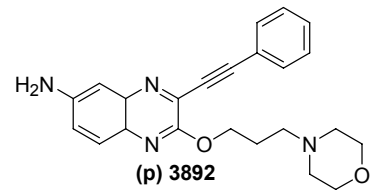

$\left(5.0 \mu \mathrm{M}=87.62 \% ; \mathrm{IC}_{50} \mathrm{SD}=0.25 \mu \mathrm{M}\right)$

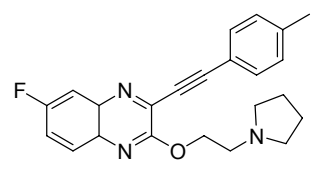

(b) 3764

$\left(2.5 \mu \mathrm{M}=85.09 \% ; \mathrm{IC}_{50} \mathrm{SD}=0.82 \mu \mathrm{M}\right)$

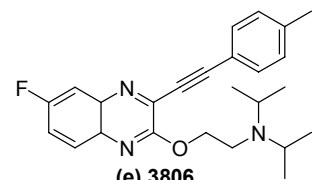

(e) 3806

$\left(2.5 \mu \mathrm{M}=82.18 \% ; \mathrm{IC}_{50} \mathrm{SD}=1.77 \mu \mathrm{M}\right)$

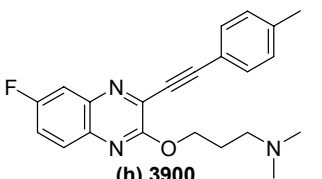

$\left(5.0 \mu \mathrm{M}=82.29 \% ; \mathrm{IC}_{50} \mathrm{SD}=2.50 \mu \mathrm{M}\right)$

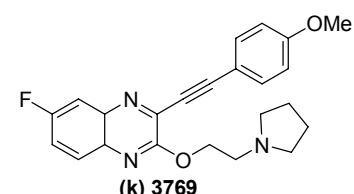

$\left(2.5 \mu \mathrm{M}=85.69 \% ; \mathrm{IC}_{50} \mathrm{SD}=1.87 \mu \mathrm{M}\right)$

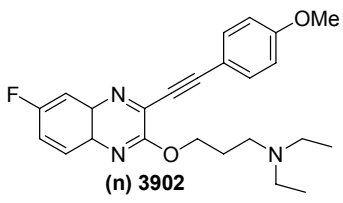

$\left(5.0 \mu \mathrm{M}=90.98 \% ; \mathrm{IC}_{50} \mathrm{SD}=1.08 \mu \mathrm{M}\right)$

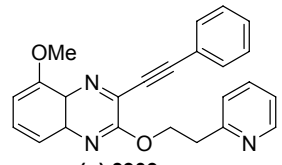

(q) 3909

$\left(5.0 \mu \mathrm{M}=86.25 \% ; \mathrm{IC}_{50} \mathrm{SD}=0.23 \mu \mathrm{M}\right)$

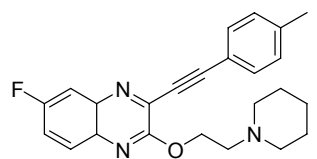

(c) 3765

$\left(2.5 \mu \mathrm{M}=86.99 \% ; \mathrm{IC}_{50} \mathrm{SD}=0.82 \mu \mathrm{M}\right)$

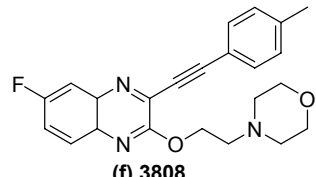

$\left(2.5 \mu \mathrm{M}=80.41 \% ; \mathrm{IC}_{50} \mathrm{SD}=1.75 \mu \mathrm{M}\right)$

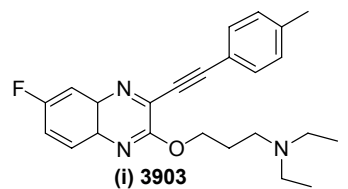

$\left(5.0 \mu \mathrm{M}=95.88 \% ; \mathrm{IC}_{50} \mathrm{SD}=1.00 \mu \mathrm{M}\right)$

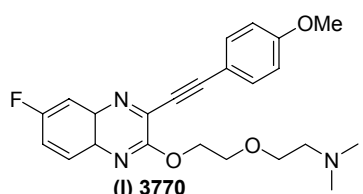

$\left(2.5 \mu \mathrm{M}=91.87 \% ; \mathrm{IC}_{50} \mathrm{SD}=0.65 \mu \mathrm{M}\right)$

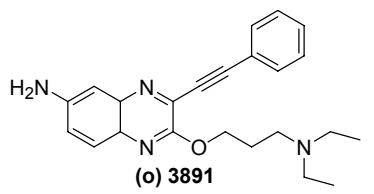

$\left(5.0 \mu \mathrm{M}=87.68 \% ; \mathrm{IC}_{50} \mathrm{SD}=0.61 \mu \mathrm{M}\right)$

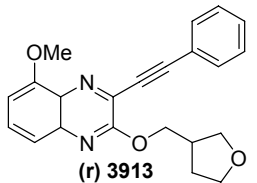

$\left(5.0 \mu \mathrm{M}=82.98 \% ; \mathrm{IC}_{50} \mathrm{SD}=0.52 \mu \mathrm{M}\right)$

Figure 1. Structure of HIF-1 $\alpha$ inhibitors based on 3-substituted phenylethynyl-2-yl-oxy quinoxaline core skeleton identified in primary screening.

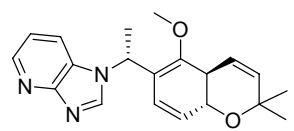

R1

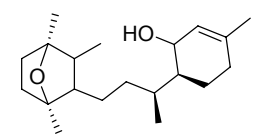

R2

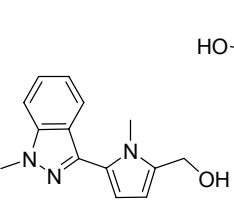

R3<smiles>O=C(O)c1cnn(-c2ccc(-c3cccc(Cl)c3)cn2)c1</smiles>

R4

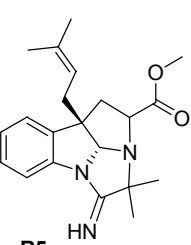

R5
Figure 2. The reference compounds in the training set obtained from prous.integrity.com site as HIF-1 $\alpha$ inhibitors for building the pharmacophore model.

pharmacophore mapping of the structure of $\mathbf{R} \mathbf{1}$, since the conformation structures of our hit compounds were similarity to those of R1, as aforementioned. The pharmacophore mapping for compound 3909, which presented the highest activity with

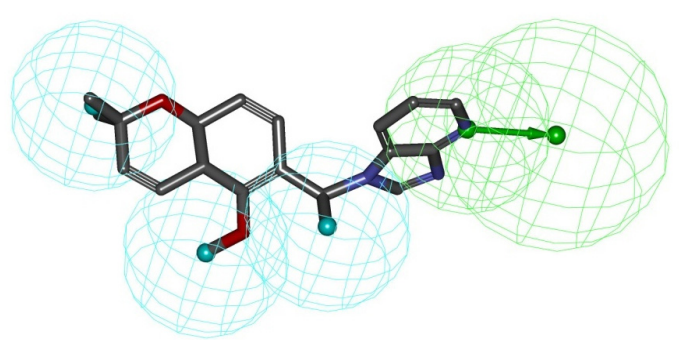

Figure 3. Pharmacophore mapping for reference compound R1, having fit value of 4.0. The green and cyan spheres represent the hydrogenbond acceptor site and the hydrophobic sites, respectively. All compounds in the training set above have a fit value of 2.9 or more.

a fit value of 2.92, is shown in Figures 4. The pharmacophore mapping for compound 3909, the 5-methoxy group and the 2-ethoxy group on the aniline group of compound 3909 had hydrophobic center roles, similar to the $4-\mathrm{NH}_{2}$ group in compounds 3892 and $\mathbf{3 8 9 1}$. The $\mathrm{N}$ atom of the pyridine ring of com- 


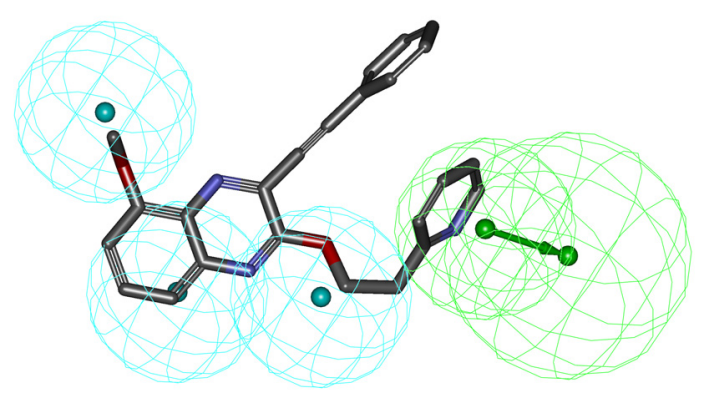

Figure 4. Pharmacophore mapping for compound 3909, having a fit value of 2.92 .

pound 3909 also played a hydrogen-bond acceptor role, like that of the nitrogen atom on the pyridine ring of R1, as shown in Figure 4 (the green sphere represents the hydrogen-bond acceptor site). The hydrogen-bond acceptor site seemed to be very important for sustaining the inhibitory activity against HIF-1 $\alpha$.

In summary, we screened 163 substituted quinoxaline small molecules, identified a novel hit core skeleton of 3-phenylethynyl-2-yl-oxy quinoxaline as a potential HIF-1 inhibitor, and demonstrated its effects in inhibiting HIF-1 $\alpha$, thereby inhibiting in the hypoxia-induced responses in vitro. Further studies are currently underway to optimize the potency and selectivity of 3-phenylethynyl-2-yl-oxy quinoxaline (Figure 1, compound 3909 ) and address their in vivo efficacy and therapeutic potential. These molecules may serve as useful mechanistic probes of the cellular function of HIF-1 $\alpha$ and the anticancer potential of biological mechanisms underlying compulsive chronic cancer agents.

\section{Experimental Procedure}

Synthetic procedures for the preparation of 5-methoxy-3phenylethynyl-2-(2-(pyridine-2-yl)ethoxy)quinoxaline (3909).
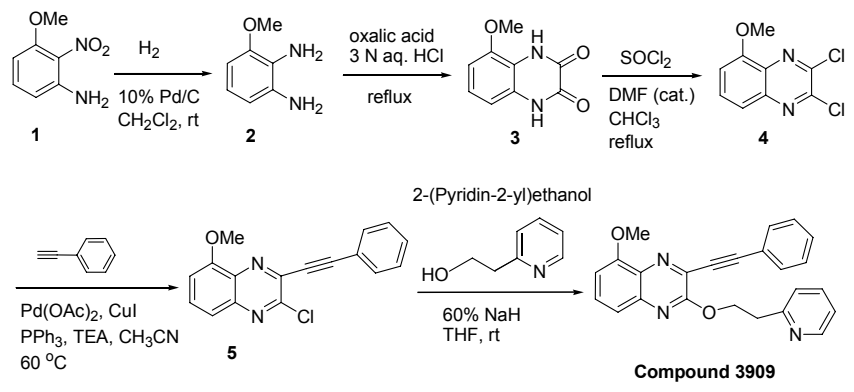

Synthesis of 3-methoxybenzene-1,2-diamine (2): A solution of 3-methoxy-4-nitro aniline (1) (10.0 g, $59.5 \mathrm{mmol})$ and $10 \%$ $\mathrm{Pd} / \mathrm{C}(\sim 1.0 \mathrm{~g})$ in dichloromethane $\left(\mathrm{CH}_{2} \mathrm{Cl}_{2}, 250 \mathrm{~mL}\right)$ was stirred under $\mathrm{H}_{2}$ gas $(\sim 20 \mathrm{psi})$ condition for 6 hours. The resulting mixture was filtered and then concentrated in vacuo to remove the solvent. The desired product 2, 3-methoxybenzene-1,2-diamine, was obtained in good yield (95\%, $7.8 \mathrm{~g}) .{ }^{1} \mathrm{H}$ NMR (500 $\left.\mathrm{MHz}, \mathrm{CDCl}_{3}\right) \delta 7.01(\mathrm{t}, J=8.1 \mathrm{~Hz}, 1 \mathrm{H}), 6.74(\mathrm{~d}, J=8.1 \mathrm{~Hz}, 1 \mathrm{H})$, $6.69(\mathrm{~d}, J=8.1 \mathrm{~Hz}, 1 \mathrm{H}), 3.80(\mathrm{~s}, 3 \mathrm{H}), 3.48(\mathrm{br} \mathrm{s}, 4 \mathrm{H})$.

Synthesis of 5-methoxy-1,4-dihydroquinoxaline-2,3-dione (3): A solution of 3-methoxybenzene-1,2-diamine (2) (5.0 g, $36.2 \mathrm{mmol})$ and oxalic acid (3.3 g, $36.2 \mathrm{mmol})$ in $3 \mathrm{~N}$ aq. $\mathrm{HCl}$
Table 1. The fit values for the selected compounds shown in Figure 1.

\begin{tabular}{cccc}
\hline Compounds & $\begin{array}{c}\text { Percentage inhibition } \\
\text { at } 2.5 \mathrm{uM}\end{array}$ & $\begin{array}{c}\mathrm{IC}_{50} \mathrm{SD} \\
(\mathrm{uM})\end{array}$ & fit value \\
\hline 3892 & 87.62 & 0.25 & 2.32 \\
3909 & 86.25 & 0.23 & 2.92 \\
\hline
\end{tabular}

$(100 \mathrm{~mL})$ was stirred at reflux condition for 24 hours. The resulting mixture was filtered and then washed with cold water and dried in vacuum oven at $50{ }^{\circ} \mathrm{C}$. The desired product 3, 4methoxy-1,4-dihydroquinoxaline-2,3-dione, was obtained in good yield $(89 \%, 6.7 \mathrm{~g}) .{ }^{1} \mathrm{H}$ NMR (300 MHz, DMSO- $\left.d_{6}\right) \delta 11.87$ (br s, 1H), 11.23 (br s, 1H), 7.04 (t, $J=8.1 \mathrm{~Hz}, 1 \mathrm{H}), 6.79$ (d, $J=$ $8.1 \mathrm{~Hz}, 1 \mathrm{H}), 6.73$ (d, $J=8.1 \mathrm{~Hz}, 1 \mathrm{H})$.

Synthesis of 5-methoxy-2,3-dichloroquinoxaline (4): To a stirred solution of 4-methoxy-1,4-dihydroquinoxaline-2,3-dione (3) $(5.0 \mathrm{~g}, 26.0 \mathrm{mmol})$ in chloroform $\left(\mathrm{CHCl}_{3}, 100 \mathrm{~mL}\right)$ was added thionyl chloride $(9.3 \mathrm{~g}, 78.0 \mathrm{mmol})$ and $N, N$-dimethylformamide (DMF, $0.5 \mathrm{~mL}$ ) at reflux condition for 24 hours. The resulting mixture was concentrated in vacuo to remove the solvent and then water was added. The desired product was filtered and washed with water and dried in a vacuum oven at $50{ }^{\circ} \mathrm{C}$. The desired product 4, 4-methoxy-2,3-dichloroquinoxaline, was obtained in good yield (78\%, $4.8 \mathrm{~g}) .{ }^{1} \mathrm{H}$ NMR (300 $\left.\mathrm{MHz}, \mathrm{CDCl}_{3}\right) \delta 7.73(\mathrm{t}, 1 \mathrm{H})$, 7.62-7.59 (m, 1H), 7.17-7.14 (m, $1 \mathrm{H})$.

Synthesis of 2-chloro-5-methoxy-3-phenyl ethynyl quinoxaline (5): To a stirred solution of 4-methoxy-2,3-dichloroquinoxaline (4) (4.27 g, $18.5 \mathrm{mmol}$ ) in dimethylsulfoxide (DMSO, $2 \mathrm{~mL}$ ) solution was added phenylacetylene $(2.3 \mathrm{~mL}, 21.3 \mathrm{mmol})$, triethylamine $(18.0 \mathrm{~mL}, 129.6 \mathrm{mmol})$, palladium(II) acetate (290 mg, $1.3 \mathrm{mmol}$ ), copper(I) iodide (437 mg, $1.7 \mathrm{mmol}$ ) and triphenylphosphine $(388 \mathrm{mg}, 2.0 \mathrm{mmol})$ at $80{ }^{\circ} \mathrm{C}$ for 2 hours. The resulting mixture was concentrated in vacuo to remove the solvent and then water was added. The mixture was extracted with ethylacetate and the organic layer was washed with water and dried over $\mathrm{MgSO}_{4}$. After removal of solvent in vacuo, the residue was purified by $\mathrm{SiO}_{2}$ column chromatography $\left(\mathrm{CH}_{2} \mathrm{Cl}_{2}\right.$ : $n$-hexane $=3: 2$ ) to yield the desired compound 5, 2-chloro-5methoxy-3-phenylethynylquinoxaline $(83 \%, 4.6 \mathrm{~g}) .{ }^{1} \mathrm{H}$ NMR $\left(300 \mathrm{MHz}, \mathrm{CDCl}_{3}\right) \delta$ 7.54-7.45 (m, 5H), $7.43(\mathrm{~m}, 2 \mathrm{H}), 7.23(\mathrm{~d}$, $1 \mathrm{H}), 4.05(\mathrm{~s}, 3 \mathrm{H})$.

Synthesis of 5-methoxy-3-(phenylethynyl-2-(2-pyridine-2yl) ethoxy) quinoxaline (Hit compound, 3909): To a stirred solution of 2-(pyridin-2-yl)ethanol (1.43 g, $11.6 \mathrm{mmol})$ in tetrahydrofuran (THF; $10 \mathrm{~mL}$ ) solution was added sodium hydride dispersion (60\%) in mineral oil (743 $\mathrm{mg}, 18.6 \mathrm{mmol})$ at room temperature for 20 minutes, after which THF $(10 \mathrm{~mL})$ solution of the prepared compound 5, 2-chloro-5-methoxy-3-phenylethynylquinoxaline $(2.75 \mathrm{~g}, 9.3 \mathrm{mmol})$, was dropped for 1 hour. Stirring was continued at room temperature for 8 hours. The resulting mixture was concentrated in vacuo to remove the solvent and then water was added. The mixture was extracted with ethylacetate and the organic layer was washed with water and dried over $\mathrm{MgSO}_{4}$. After removal of solvent in vacuo, the residue was purified by $\mathrm{SiO}_{2}$ column chromatography $\left(\mathrm{CH}_{2} \mathrm{Cl}_{2}\right.$ : Ethanol $=9: 1)$ to yield the desired compound 3909, 5-methoxy-3-(phenylethynyl-2-(2-pyridine-2-yl) ethoxy) quinox- 
aline $(79 \%, 2.84 \mathrm{~g}) .{ }^{1} \mathrm{H}$ NMR $\left(500 \mathrm{MHz}, \mathrm{CDCl}_{3}\right) \delta 8.56(\mathrm{~d}, J=$ $4.8 \mathrm{~Hz}, 1 \mathrm{H}), 7.60-7.62(\mathrm{~m}, 3 \mathrm{H}), 7.51-7.54(\mathrm{~m}, 3 \mathrm{H}), 7.48(\mathrm{t}, J=$ $8.1 \mathrm{~Hz}, 1 \mathrm{H}), 7.37-7.43(\mathrm{~m}, 4 \mathrm{H}), 7.11-7.14(\mathrm{~m}, 1 \mathrm{H}), 7.06(\mathrm{~d}, J=$ $7.9 \mathrm{~Hz}, 1 \mathrm{H}), 4.99(\mathrm{t}, J=6.5 \mathrm{~Hz}, 2 \mathrm{H}), 4.05(\mathrm{~s}, 3 \mathrm{H}), 3.42(\mathrm{t}, J=$ $6.5 \mathrm{~Hz}, 2 \mathrm{H})$; MS (ESI) $m / z 382\left([\mathrm{M}+\mathrm{H}]^{+}\right)$.

Materials for screening: Cell culture medium, fetal bovine serum (FBS), and horse serum were obtained from Invitrogen (Gaithersburg, MD, USA). As the substrate of the prolyl hydroxylase domain (PHD2) enzyme, an 18-mer peptide [DLDLEALAPYIPADDFQ], was synthesized by AnyGen Co. Ltd. (Kwangju, Korea). The 18-mer peptide matches the amino acid residues 556 to 575 of HIF- $1 \alpha$. To identify the PHD activators, chemical compounds were obtained from the Korea Research Institute of Chemical Technology (Daejeon, Korea). All other chemicals were purchased from Sigma (St. Louis, MO, USA) and/or were the same as described.

Inhibitory efficacy test of the compounds on cancer cell proliferation: To evaluate the anti-cancer effect of the synthetic compounds, the colon cancer cell line HCT116 was used to test the inhibitory effect on cancer cell proliferation. HCT116 was cultured with Dulbecco's Modified Eagle Medium (DMED) containing $10 \%$ FBS at $37{ }^{\circ} \mathrm{C}$.

Cell culture: HCT 116 cells cultured in T75 were transferred to 96-well plates as follows. When cells reached a confluence, they were trypsinized using trypsin-EDTA solution for $5 \mathrm{mi}$ nutes after washing with phosphate-buffered saline (PBS). Subsequently, $10 \mathrm{~mL}$ of culture media was added and the mixture was centrifuged at 1,500 rpm for 3 minutes. The supernatant was aspirated out and the cell pellet was resolved in $10 \mathrm{~mL}$ of culture media. The cells were counted and transferred to a 96well plate at 5,000 cells $/ 100 \mu \mathrm{L} /$ well. The cells were incubated for 24 hours in a $\mathrm{CO}_{2}$ incubator.

Measurement: After 72 hours of incubation, $20 \mu \mathrm{L}$ of MTS solution (CellTiter 96 Aqueous one solution cell proliferation assay) was added and incubated for 1 hour. The reaction was measured using a Thermo-MAX microplate reader (Molecular Devices) at $490 \mathrm{~nm}$.

Inhibitory efficacy test of compounds on HIF binding using reporter assay system.

Principle of experiment: Hypoxic conditions were induced to HIF-1 $\alpha$ using an HRE/SW480 stable cell line containing HRE-luc[pHTS-9XHRE-Luc]. ${ }^{1,20}$ Once HIF- $1 \alpha$ was induced, the HRE promoter was activated by binding with HIF-1 $\alpha$, which in turn activated the reporter gene, luciferase. In this way, the compounds could be tested for the inhibition of HIF- $1 \alpha$ activation.

Experimental method: To achieve hypoxic conditions, 100 $\mu \mathrm{M}$ of $\mathrm{CoCl}_{2}$ was treated on a [pHTS-9XHRE-Luc] SW480 cell line for 24 hours. After compound treatment with a series of concentrations for 20 hours, luciferase activity was measured using Bright-glo (promega).

Computational method: We selected 67 compounds from prous.integrity.com site as HIF-1 inhibitors. After the 3D structures of these compounds were generated using CONCORD, ${ }^{16}$ they were minimized using Gasteiger-Huckel charges and conjugated gradient methods. In order to consider the structural redundancy of the subset, we carried out a maximum dissimilarity study using Extended Connectivity Fingerprints (ECFP). ${ }^{19}$ We selected 5 compounds as the training set, as shown in Figure 1. The pharmacophores with common features were generated using the HipHop algorithm. ${ }^{17}$ Predefined pharmacophore features were used to automatically create the pharmacophore hypothesis model. The list of features of the minimum and maximum values was as follows: $\mathrm{H}$-bond acceptor $(\mathrm{Hba}) 0$ and 5, H-bond donor (Hbd) 0 and 5, Hydrophobic (Hy) 0 and 5.

Acknowledgments. This research was supported by the Basic Science Research Program through the National Research Foundation of Korea (NRF) funded by the Ministry of Education, Science and Technology (grant number 2010-0004128) and the Ministry of Knowledge Economy, Korea.

\section{References}

1. Semenza, G. L. Drug Discov. Today 2007, 12, 853.

2. Jiang, B. H.; Rue, E.; Wang, G. L.; Roe, R. J.; Semenza. G. L. J. Biol. Chem. 1996, 271, 17771.

3. Wang, G. L.; Semenza, G. L. J. Biol. Chem. 1995, 270, 1230.

4. Kaelin, W. G. Annu. Rev. Biochem. 2005, 74, 115.

5. Lee, K.; Lee, J. H.; Boovanahalil, S. K.; Jin, Y.; Lee, M.; Jin, X.; Kim, J. H.; Hong, Y.-S.; Lee, J. J. J. Med. Chem. 2007, 50, 1675.

6. Giaccia, A.; Siim, B. G.; Johnson, R. S. Nat. Rev. Drug Discovery 2003, $2,1$.

7. Choi, H. J.; Song, B.-J.; Gong, Y.-D.; Gwak, W. J.; Soh, Y. British J. Pharm. 2008, 154, 114.

8. Chalet, T.; Rita, G. N.; Anthony, J. R.; Beata, P.; Fatima, K.; Zhaobin, Z.; Huanchun, Z.; Quincy, T.; Ainsley, C. N.; Paraskevi, G.; Wei, Z.; Jeffrey, J. O.; Manuela, M. P.; Nicolaou, K. C.; Erwin, G. V. M. Cancer Res. 2005, 65, 605

9. Jeon, M.-K.; Kim, D.-S.; La, H. J.; Gong, Y.-D. Tetrahedron Lett. 2005, 46, 4979.

10. Gong, Y.-D.; Jeon, M.-K.; Hwang, S. H.; Dong, M. S.; Lee, S. B.; Kang, K. H.; Oh, C. H. Kor. Pat. 0889389, 2009.

11. Gong, Y.-D.; Jeon, M.-K.; Hwang, Lee, Th.; Hwang, S. H.; Yoo, S.-e. Kor. Pat. Appl. 2008-0016257, 2008.

12. Amar, G. C.; Gundluru, M. K.; Kumar, P. B. C.; Yang, L.; YuDong, Z.; Dale, G. N.; Mitchell A. A. J. Med. Chem. 2007, 50, 6299.

13. Park, J. W.; Chun, Y. S.; Kenneth, B.; Sho, H. S. WO 2005030121. 2005.

14. Warshakoon, N. C.; Wu, S.; Boyer, A.; Kawamoto, R.; Renock, S.; Xu, K.; Pokross, M.; Evdokimov, A. G.; Zhou, S.; Winter, C.; Walter, R.; Mekel, M. Bioorg. Med. Chem. Lett. 2006, 16, 5687.

15. Ventosa-Andres, P.; Gonzalez-Vera, J. A.; Valdivielso, A. M.; Teresa Garcia-Lopez, M.; Herranz, R. Bioorg. Med. Chem. 2008, $16,9313$.

16. Concord; Tripos Inc., 1699 South Hanley Road, St. Louis, MO 63144.

17. Sprague, P. W. Automated Chemical Hypothesis Generation and Database Searching with Catalyst. In Perspectives in Drug Discovery and Design; Müller, K., Ed.; ESCOM Science Publishers B. V.: Leiden, The Netherlands, 1995; Vol. 3, pp 1-20.

18. Gong, Y.-D.; Kang, N. S. Bull. Korean Chem. Soc. 2010, 31, 2039.

19. Hert, J.; Willett, P.; Wilton, D. J.; Acklin, P.; Azzaoui, K.; Jacoby, E.; Schuffenhauer, A. J. Chem. Inf. Comp. Sci. 2004, 44, 1177.

20. Han, Z. B.; Ren, H.; Zhao, H.; Chi, Y.; Chen, K.; Zhou, B.; Liu, Y. J.; Zhang, L.; Xu, B.; Liu, B.; Yang, R.; Han, Z. C. Carcinogenesis 2008, $29,1853$. 